\title{
PENILAIAN PELAKSANAAN SUPERVISI AKADEMIK PENGAWAS SMK NEGERI DI KABUPATEN TAKALAR
}

\author{
Oleh : Abdul Azis \\ Universitas Negeri Makassar Jl. Bonto Langkasa, Makassar -90222, Tlp. \\ (04011) 830366, tlp/fax. (0411) 855288, E-mail: Pasca@unm.ac.id, \\ Website: http://www.pps.unm.ac.id
}

\begin{abstract}
Abstrak
Penelitian ini bertujuan untuk mengetahui: (1). Pelaksanaan supervisi akademik pengawas SMK Negeri dalam aspek pemantauan berdasarkan penilaian guru. (2). Pelaksanaan supervisi akademik pengawas SMK Negeri dalam aspek penilaian berdasarkan penilaian guru, (3). Pelaksanaan supervisi akademik pengawas SMK negeri dalam aspek pembimbingan/pelatihan berdasarkan penilaian guru.

Penelitian ini bersifat penelitian survei, yang dilakukan di sekolah SMK Negeri di Kabupaten Takalar dengan sampel penelitian adalah guru dengan jumlah responden 80 guru. Instrumen penelitian yaitu menggunakan lembar observasi, pedoman penilaian, dan pedoman wawancara. Teknik pengumpulan data yaitu observasi, menyebar pedoman penilaian, wawancara dan daftar hadir guru.

Berdasarkan hasil penelitian diperoleh bahwa penilaian guru terhadap pelaksanaan supervisi akademik pengawas SMK negeri dalam aspek pemantauan cukup baik dengan skor 73 atau 91,25 persen. Penilaian guru terhadap pelaksanaan supervisi akademik pengawas SMK negeri dalam aspek penilaian kurang baik dengan skor 46 atau 57,50 persen, kemudian penilaian guru terhadap pelaksanaan supervisi akademik pengawas SMK negeri dalam aspek pembimbingan/pelatihan kategori cukup baik dengan skor 48 orang atau 60,00 persen.
\end{abstract}

Kata kunci: Supervisi Akademik, Pengawas Sekolah, Penilaian 


\begin{abstract}
The study aims at examining (1) the implementation of academic supervision of supervisors at SMKN on the aspect of monitoring based on teachers' evaluation, (2) the implementation of academic supervision of supervisors at SMKN on the aspect of evaluation based on the teachers' evaluation, and (3) the implementation of academic supervision of supervisors at $S M K N$ on the aspect of guidance based on the teachers' evaluation.

The study is a survey research which conducted at SMKN in Takalar district. The samples were 80 teachers. The instruments were observation sheet, guided evaluation, and guided interview. Data were collected through observation, guided evaluation, interview, and attendance list of teachers.

The results of the study revealed that teachers' evaluation on the implementation of academic supervision of supervisors at SMKN on the aspect of monitoring was fairly good with the score 73 or 91.25\%. The teachers' evaluation on the implementation of academic supervision of supervisors at SMKN on the aspect of evaluation was poor with the score 46 or $57.50 \%$. The teachers' evaluation on the implementation of academic supervision of supervisors at SMKN on the aspect of guidance was in fairly good category with the score 48 or $60.00 \%$.
\end{abstract}

Keywords: Academic Supervision, School Supervisor, Assesment

\title{
Pendahuluan
}

Pengawas sekolah merupakan tenaga kependidikan yang harus memahami dan menguasai kompetensi pengawas. Peraturan Menteri Pendidikan Nasional RI Nomor 12 Tahun 2007 Tentang Standar Pengawas Sekolah/Madrasah menegaskan bahwa seorang pengawas harus memiliki 6 (enam) kompetensi minimal, yaitu kompetensi sosial, kompetensi kepribadian, supervisi manajerial, supervisi akademik, evaluasi pendidikan, penelitian dan pengembangan.

Pengawas Sekolah/madrasah adalah salah satu unsur yang berperan aktif dalam lembaga pendidikan (persekolahan) atau pelaku pendidikan didalam pelaksanaan tugas kepengawasan pendidikan yang meliputi tiga aspek yaitu supervisi, pengendalian (kontroling) dan inspeksi kependidikan. Di sampin itu juga pengawas sekolah merupakan tenaga kependidikan yang posisinya memegang peran yang penting dan strategis dalam meningkatkan profesionalisme guru dan mutu pendidikan di sekolah. 
Akhir-akhir ini pengawas sekolah telah mendapat beragam tanggapan baik dari media maupun dari praktisi pendidikan, dari enam dimensi kompetensi pengawas sekolah ternyata ada tiga dimensi kompetensi yang paling lemah/rendah yakni kompetensi supervisi akademik, supervisi manajerial dan kompetensi penelitian dan pengembangan. Sebaliknya dimensi kompetensi penelitian yang paling tinggi adalah kompetensi kepribadian dan sosial (Sudjana, 2011b:185).

Lemahnya ketiga kompetensi ini menunjukkan pembinaan para pengawas yang dilaksanakan tidak secara terencana dan berkesinambungan yang mengarah pada kemampuan profesional para pengawas serta pengembangan karirnya sebagai tenaga fungsional.

Guru merupakan salah satu komponen pendidikan yang mempunyai perang penting dalam menentukan mutu pendidikan sebab gurulah sebagi aktor utama untuk menterjemahkan kurikulum dalam pembelajaran di kelas. Pencapaian tujuan pendidikan akan sangat berpengaruh oleh kemampuan guru dalam melaksanakan tugasnya. Dalam melaksanakan tugasnya tidak sedikit masalah yang sering dihadapi oleh guru yang berkaitan pembelajaran di sekolah sehingga guru perlu mendapatkan bantuan orang lain khususnya pengawas sekolah. Salah satu bantuan yang dapat diberikan oleh pengawas adalah bantuan berupa supervisi akademik. Supervisi akademik adalah bantuan yang bersifat profesional kepada guru dalam membantu kemampuan profesionalismenya. Glickman dalam Asmani (2012: 92) mengemukakan bahwa supervisi akademik adalah serangkaian kegiatan yang dapat membantu guru dalam pengembangan kemampuannya mengelola proses pembelajaran demi tercapainya tujuan pendidikan.

Sebagai gambaran umum pengawas sekolah SMK di kabupaten Takalar bahwa dalam rekrutmen yang dilakukan oleh dinas pendidikan kurang mempertimbangkan aspek kompetensi dan prestasi seseorang, tetapi cenderung dipengaruhi oleh pertimbangan politis, penunjukan langsung oleh pemerintah daerah tanpa melalui seleksi, ada kepala sekolah atau guru tiba-tiba ditunjuk menjadi pengawas sekolah tanpa memperhatikan kompetensi dan prestasi yang 
dimilikinya, hal ini berefek kepada kemampuan pengawas dalam melaksanakannya misalnya kemampuan dalam melaksanakan supervisi terhadap guru binaannya.

Ditinjau dari segi kualifikasi pendidikan pengawas masih ada yang belum magister, walaupun ada yang sudah magister tetapi kualifikasinya mayoritas dari non pendidikan. Dari data yang diperoleh bahwa pengawas sekolah SMK negeri di Kabupaten Takalar berjumlah 7 orang, ada 2 orang pengawas kualifikasi pendidikan terakhirnya $\mathrm{S}_{1}, 4$ orang kualifikasi pendidikan terakhir magister non pendidikan dan 1 orang kualifikasi pendidikan terakhir magister pendidikan. Dengan kualifikasi pendidikan pengawas yang ada terasa belum cukup untuk menjamin kompetensi atau kemampuan pengawas dalam melaksanakan tugastugasnya yaitu membantu guru dalam meningkat kualitas pendidikan.

Berkaitan dengan pelaksanaan supervisi akademik yang berhubungan dengan 4 Standar Nasional Pendidikan (SI, SKL, Standar Proses dan Standar Penilaian), ada beberapa hal dirasakan masih perlu diperbaiki terhadap pelaksanaan supervisi akademik. Supervisi yang dilakukan pengawas di Kabupaten Takalar ternyata masih kurang. Hal ini dapat dilihat dari pemantauan, penilaian dan pembimbingan. Pemantauan diartikan sebagai kegiatan pencatatan, perekaman atau peristiwa yang terjadi pada waktu guru melaksanakan pembelajaran. Fakta dilapangan menunjukkan bahwa frekuensi pengawas dalam memantau di sekolah umumnya hanya satu kali persemester. Tentu hal ini kurang memadai sebagai supervisor untuk membantu peningkatan mutu pendidikan.

Semiawang dalam Masaong (2012: 4) menjelaskan bahwa sistem supervisi yang kurang memadai karena dipengaruhi oleh beberapa aspek, antara lain: (1) supervisi masih menekankan pada aspek administrasi dan mengabaikan aspek profesional, (2) tatap muka antara supervisor dengan guru-guru sangat sedikit, (3) supervisor sudah lama tidak mengajar, sehingga banyak dibutuhkan bekal tambahan agar dapat mengikuti perkembangan, (5) potensi guru sebagai pembimbing kurang dimanfaatkan. Dengan demikian hal ini akan berakibat 
kurangnya pemantauan pengawas terhadap pencapaian ketuntasan keempat standar tersebut.

Demikian pula dengan hal melakukan penilaian pengawas sekolah cenderung kurang teliti dalam menilai guru. Penilaian diartikan suatu kegiatan pengumpulan, pengolahan, interpretasi dari informasi untuk mengambil keputusan berdasarkan kriteri-kriteria yang ditentukan (Iskandar, 2013). penilaian seharusnya dilakukan secara teliti terhadap dokumen maupun pelaksanaan di kelas biasanya hanya secara subyektif tanpa melihat kondisi yang real. Padahal data yang diperoleh ini bisa dimanfaatkan dan dianalisis oleh pengawas bersama guru dalam rangka menyusun suatu program yang sesuai untuk memperbaiki kondisi pembelajaran yang ada.

Terlebih lagi dalam hal pembimbingan/pelatihan. Pembimbingan diartikan upaya yang dilakukan oleh pengawas sekolah terhadap guru-guru dalam membantu memperbaiki proses pembelajaran agar lebih berkualitas pembelajarannya. Pembimbingan seyogyanya dilakukan terhadap guru-guru yang membutuhkan bimbingan/pelatihan, seperti perencanaan pembelajaran, bagaimana model-model pembelajaran yang bervariasi tidak membosankan siswa, penggunaan media yang sesuai, bagaimana menyusun butir soal yang sesuai dengan indikator pencapaian, bagaimana seorang guru mampu membuat PTK yang dapat memperbaiki proses pembelajaran di sekolah ternyata masih banyak guru yang belum sesuai dengan harapan.

Guru dan pengawas merupakan mitra dalam kegiatan pembelajaran di sekolah terutama di sekolah binaannya sebab dengan kemitraan dan saling terbuka yang dilandasi pendekatan komunikatif kegiatan supervisi akademik dapat berlangsung efektif. Keefektifan pelaksanaan supervisi akademik pengawas sekolah terhadap guru akan terasa dilakukan seperti memantau, menilai, dan membimbing/pelatihan selama ini, dengan demikian guru dapat memberikan penilaian terhadap pelaksanaan supervisi akademik, khususnya pelaksanaan supervisi akademik pengawas SMK di Kabapaten Takalar. Berdasarkan uraian di 
atas maka peneliti tertarik melakukan penelitian untuk mengetahui Penilaian Pelaksanaan Supervisi Akademik Pengawas SMK Negeri Di Kabupaten Takalar.

Berdasarkan latar belakang yang telah diuraikan di atas, maka pertanyaan penelitian yang dijadikan sebagai sasaran dalam penelitian ini sebagai berikut: “bagaimanakah pelaksanaan supervisi akademik pengawas sekolah SMK negeri dalam aspek pemantauan berdasarkan penilaian guru ?, bagaimanakah pelaksanaan supervisi akademik pengawas sekolah SMK negeri dalam aspek penilaian berdasarkan penilaian guru ?, bagaimanakah pelaksanaan supervisi akademik pengawas sekolah SMK negeri dalam aspek pembimbingan/pelatihan berdasarkan penilaian guru ?.

Berdasarkan pertanyaan penelitian di atas maka tujuan penelitian yang ingin dicapai ini adalah untuk mengetahui untuk mengetahui; pelaksanaan supervisi akademik pengawas sekolah SMK negeri dalam aspek pemantauan berdasarkan penilaian guru; untuk pelaksanaan supervisi akademik pengawas sekolah SMK negeri dalam aspek penilaian berdasarkan penilaian guru; untuk mengetahui pelaksanaan supervisi akademik pengawas sekolah SMK negeri dalam aspek pembimbingan/pelatihan berdasarkan penilaian guru. Adapun manfaat penelitian ini adalah; Sebagai masukan dan bahan pertimbangan bagi Kepala Dinas Pendidikan Kebudayaan, Pemuda dan Olahraga dalam mengambil kebijakan untuk meningkatkan mutu pendidikan di Kabupaten Takalar; hasil penelitian ini diharapkan dapat menggugah dan mendorong (memotivasi) para pengawas sekolah untuk terus meningkatkan pelaksanaan supervisi akademik seperti pemantauan, penilaian dan pembimbingan/pelatihan terhadap sekolah binaannya; dapat memberikan manfaat bagi pengembang ilmu pengetahuan serta dapat dijadikan sebagai referensi kelengkapan sumber data bagi yang lain yang berkaitan dengan judul tersebut. 


\section{Tinjauan Teoretis}

Salah satu kompetensi yang harus dimiliki dan dikuasai pengawas sekolah sebagai supervisor pendidikan adalah kompetensi supervisi akademik. Supervisi akademik dapat diartikan sebagai bantuan profesional/keahlian kepada guru agar guru dapat mempertinggi kualitas pembelajaran dalam mata pelajaran yang diampuh (Sudjana 2012b: 16). Inti supervisi akademik adalah membina guru di sekolah dalam meningkatkan mutu proses pembelajaran, oleh karena itu sasarannya adalah guru dalam proses pembelajaran, yang terdiri atas materi pokok dalam proses pembelajaran, penyusunan silabus dan RPP, pemilihan strategi/metode/teknik pembelajaran, penggunaan media dan teknologi informasi dalam pembelajaran serta penelitian tindakan kelas, Prosojo \& Sudiono dalam (Asmani 2012: 98).

Peraturan Menteri Negara Pendayagunaan Aparatur Negara dan Reformasi Birokrasi RI Nomor 21 Tahun 2010 Pasal 5, menyatakan bahwa Tugas pokok pengawas sekolah adalah melaksanakan supervisi akademik dan supervsi manajerial pada satuan pendidikan yang meliputi penyusunan program kepengawasan, pelaksanaan pembinaan, pemantauan 8 (delapan) Standar Nasional Pendidikan, penilaian, pembimbingan dan pelatihan profesional guru, evaluasi hasil pelaksanaan program pengawasan, dan pelaksanaan pengawasan di daerah khusus.

Pemantauan pelaksanaan empat standar nasional pendidikan adalah kegiatan mengamati, merekam dan mencatat pelaksanaan empat standar nasional pendidikan di sekolah yang menjadi tanggung jawab guru. Menurut (Sudjana, Dharma, \& Westandar, (2012b:1) bahwa pelaksanaan standar nasional pendidikan yang menjadi tanggung jawab guru adalah: (a) standar kompetensi kelulusan, (b) standar isi, (c) standar proses, dan (d) standar penilaian. Kemudian kegiatan pelaksanaan penilaian pengawas dimaksudkan untuk mastikan keberlangsungan dan kegiatan kemampuan guru dalam hal perencanaan, pelaksanaan dan penilaian pembelajaran di sekolah. Menurut Suhardan (2009: 315), bahwa kegiatan 
penilaian berupa usaha untuk mengetahui segala fakta yang mempengaruhi kelangsungan persiapan, penyelenggaraan dan hasil pembelajaran.

Bimbingan merupakan salah satu bentuk helping atau bantuan yang diberikan kepada seseorang yang membutuhkan. Sudjana (2013: 44), menjelaskan Pembimbingan adalah kegiatan memberi bantuan kepada sesorang atau lebih agar yang bersangkutan dapat mengatasi masalah yang dihadapinya.

Sukmadinata (2004: 235), menjelaskan bahwa bimbingan adalah suatu usaha yang dilakukan oleh seorang pembimbingan atau konselor didalam membantu memecahkan masalah. Sedangkan Smith dalam Herris (2011), bimbingan adalah sebagai proses layanan yang diberikan kepada individu-individu guna membantu mereka memperoleh pengetahuan dan keterampilan yang diperlukan dalam membuat pilihan-pilihan, rencana-rencana, dan interpretasi-interpretasi yang diperlukan untuk menyesuaikan diri dengan baik.

\section{Metode Penelitian}

Jenis penelitian ini adalah penelitian survei yaitu penelitian yang dilakukan untuk memperoleh gambaran umum tentang karakteristik populasi. Dalam penelitian ini, karakteristik yang dikaji adalah penilaian pelaksanaan supervisi akademik pengawas SMK Negeri di Kabupaten Takalar. Desain penelitian ini adalah menggunakan pendekatan kuantitatif, karena data yang dihasilkan berupa data kuantitatif dan kualitatif. Data kuantitatif diperoleh melalui pedoman penilaian dan dokumentasi serta observasi sedang data kualitatif diperoleh melalui wawancara.

Populasi penelitian ini adalah semua guru di Sekolah Menengah Kejuruan Negeri di Kabupaten Takalar yang berjumlah 7 sekolah dengan jumlah guru sebanyak 314 orang. Cara penarikan sampel dalam penelitian ini menggunakan sampel acak proporsional atau Proporsional Random Sampling. Sedangkan teknik pengambilan sampel menggunakan rumus dari Taro Yamane atau Slovin dalam

Riduwan (2009: 95), $\mathrm{n}=\frac{\mathrm{N}}{\mathrm{Ne}^{2}+1}$, ukuran sampel dalam penelitian ini sebesar 80 
orang, ini berarti di atas sampel minimal berdasarkan rumus Slovin. Penambahan ini dilakukan sebagai antisipasi jika pada saat pengambilan data terdapat responden yang berhalangan.

Dalam penelitian ini teknik pengumpulan data yang digunakan untuk mengumpulkan data sebagai berikut; lembar penilaian, wawancara, observasi dan dokumentasi. Data yang telah dikumpulkan, diolah dengan menggunakan teknik statistik deskriptif. Teknik statistik deskriptif dimaksudkan untuk mendeskripsikan gambaran penilaian pelaksanaan supervisis akademik pengawas sekolah berdasarkan penilaian guru SMK negeri dengan tabel distribusi frekuensi, modus dan persentase.

Pengukuran dalam penelitian ini, menggunakan lembar penilaian atau rubrik yang disusun berdasarkan skala model Likert. Respon diharapkan memberi jawaban pada salah satu pilihan jawaban yang disediakan pada setiap pertanyaan yang diajukan dengan memberi tanda centang $(\sqrt{ })$ pada pilihan jawaban.

Untuk menentukan kualitas kondisi variabel, digunakan kategori sebagai berikut.

Tabel 3.6 Kategori penilaian pelaksanaan supervisi akademik pengawas sekolah

\begin{tabular}{ccc}
\hline Interval & Kualifikasi & Kategori \\
\hline $76-100$ & A & Amat baik \\
\hline $51-75$ & B & Baik \\
\hline $26-50$ & C & Cukup baik \\
\hline$\leq 25$ & D & Kurang baik
\end{tabular}

Sumber: Direktorat Jenderal Manajemen Pendidikan Dasar dan Menengah (2010: 2)

Uji validitas dilakukan terhadap pedoman penilaian yang digunakan dalam penelitian ini . tujuan dari uji validitas adalah untuk mengetahui apakah pedoman penilaian tersebut relevan atau dapat dipercaya. Pengujiannya dilakukan secara 
statistik. Uji coba ini dilakukan terhadap 49 responden. Dasar pengambilan keputusan uji validitas adalah membandingkan nilai setiap butir responden dengan total jumlah butir dengan nilai r tabel, dengan taraf signifikan $5 \%$. Uji reliabilitas dilakukan terhadap pedoman penilaian yang digunakan dalam penelitian ini. Dalam penelitian ini akan digunakan dengan uji Cronbach's Alpa, digunakan uji Cronbach’s Alpa karena pilihan jawaban lebih dari dua.

\section{Hasil Penelitian}

\section{Aspek pemantauan pengawas sekolah}

Penilaian pelaksanaan supervisi akademik pengawas SMK Negeri di Kabupaten Takalar oleh guru dalam aspek pemantauan dapat dilihat di bawah ini. Tabel 4.8 Identifikasi aspek pemantauan pengawas sekolah

\begin{tabular}{cccc}
\hline Interval & Kategori & Frekuensi & Persentase \\
\hline $76-100$ & Amat baik & 0 & 0,00 \\
\hline $51-75$ & Baik & 0 & 0,00 \\
\hline $26-50$ & Cukup baik & 73 & 91,25 \\
\hline$\leq 25$ & Kurang baik & 7 & 8,75 \\
\hline & Jumlah & $\mathbf{8 0}$ & $\mathbf{1 0 0}$ \\
\hline
\end{tabular}

Berdasarkan data pada tabel 4.8 diperoleh gambaran pelaksanaan supervisi akademik pengawas sekolah dari 80 responden, yang menyatakan kurang baik sebanyak 7 orang atau 8,75 persen, cukup baik 73 orang atau 91,25 persen dan tidak ada responden yang menyatakan amat baik maupun baik. Dengan demikian dapat disimpulkan bahwa penilaian pelaksanaan supervisi akademik pengawas sekolah dalam aspek pemantauan kategori cukup baik.

\section{Aspek penilaian pengawas sekolah.}

Penilaian pelaksanaan supervisi akademik pengawas SMK negeri di Kabupaten Takalar oleh guru dalam aspek penilaian dapat dilihat di bawah ini. 
Tabel 4.9 Identifikasi aspek penilaian pengawas sekolah

\begin{tabular}{cccc}
\hline Interval & Kategori & Frekuensi & Persentase \\
\hline $76-100$ & Amat baik & 0 & 0,00 \\
\hline $51-75$ & Baik & 0 & 0,00 \\
\hline $26-50$ & Cukup baik & 34 & 42,50 \\
\hline$\leq 25$ & Kurang baik & 46 & 57,50 \\
\hline & Jumlah & $\mathbf{8 0}$ & $\mathbf{1 0 0}$ \\
\hline
\end{tabular}

Berdasarkan data pada tabel 4.9 diperoleh gambaran pelaksanaan supervisi akademik pengawas sekolah dari 80 responden, yang menyatakan kurang baik sebanyak 46 orang atau 57,50 persen, cukup baik 34 orang atau 42,50 persen dan tidak ada responden yang menyatakan baik dan amat baik. Dengan demikian dapat disimpulkan bahwa penilaian pelaksanaan supervisi pengawas sekolah dalam hal penilaian kategori kurang baik.

\section{Aspek pembimbingan/pelatihan pengawas sekolah}

Penilaian pelaksanaan supervisi akademik pengawas SMK Negeri di Kabupaten Takalar oleh guru dalam aspek pembimbingan/pelatihan dapat dilihat di bawah ini.

Tabel 4.10 Identifikasi aspek pembimbingan/pelatihan pengawas sekolah

\begin{tabular}{cccc}
\hline Interval & Kategori & Frekuensi & Persentase \\
\hline $76-100$ & Amat baik & 0 & 0,00 \\
\hline $51-75$ & Baik & 29 & 36,25 \\
\hline $26-50$ & Cukup baik & 48 & 60,00 \\
\hline$\leq 25$ & Kurang baik & 3 & 3,75 \\
\hline & Jumlah & $\mathbf{8 0}$ & $\mathbf{1 0 0}$ \\
\hline
\end{tabular}


Berdasarkan data pada tabel 4.10 diperoleh gambaran pelaksanaan supervisi akademik pengawas sekolah dari 80 responden, yang menyatakan kurang baik sebanyak 3 orang atau 3,75 persen, cukup baik 53 orang atau 60,00 persen, baik 29 orang atau 36,25 persen dan tidak ada responden yang menyatakan amat baik. Dengan demikian dapat disimpulkan bahwa penilaian pelaksanaan supervisi akademik pengawas sekolah dalam hal pembimbingan/pelatihan kategori cukup baik.

Selanjutnya data hasil observasi ketersediaan dokumen-dokumen dari 10 guru. Ketersediaan dokumen silabus ada 10 guru atau 100\%, ketersediaan dokumen RPP terbaru ada 8 guru atau 80\%, Ketersediaan program tahunan terbaru 10 guru atau 100\%, ketersedian dokumen program semester terbaru ada 10 orang atau $100 \%$. Ketersediaan kisi-kisi soal mata pelajaran ada 8 guru atau $80 \%$, ketersediaan dokumen analisis tingkat kesukaran butir soal ada 3 guru atau 30\%, ketersediaan dokumen analisis daya pembeda butir soal ada 3 guru atau $30 \%$. Ketersediaan dokumen analisis reliabilitas instrumen ada 1 guru atau 10\%, dan ketersediaan dokumen penelitian tindakan kelas (PTK) tidak ada.

\section{Pembahasan}

Dari hasil analisis data, diperoleh hasil pemantauan pengawas sekolah dalam pelaksanaan supervisi akademik tergolong cukup baik dengan skor 73 atau 91,25. Arinya pemantauan pelaksanaan supervisi akademik sudah berjalan, meskipun hanya level cukup. Level cukup baik, ini bisa jadi guru merasa pengawas sekolah seharusnya pemantauan pengawas bukan hanya saat-saat supervisi terpadu atau supervisi gabungan, akan tetapi diwaktu-waktu lainnya pengawas intensitas kehadirannya perlu diperhatikan atau ditingkatkan dengan bentuk diskusi atau tanya jawab, kunjungan kelas dan memberikan informasiinformasi baru, dengan demikian guru lebih tertarik kehadirannya pengawas, memahami tugas dan fungsi pengawas yang dilakukan. 
Dari hasil analisis data diperoleh data bahwa penilaian pelaksanaan supervisi akademik pengawas SMK Negeri di Kabupaten Takalar dalam hal penilaian, tergolong kurang baik dengan skor 46 atau 57,50. Rendahnya penilaian pelaksanaan supervisi akademik pengawas oleh guru menjadi ukuran dalam pelaksanaan supevisi akademik yang dinilai guru dalam kaitannya dengan pembelajaran di sekolah, sehingga kedepannya pengawas sekolah akan lebih aktif melakukan komunikasi terhadap guru, keterbukaan dalam aspek-aspek penilaian dan ketelitian ketika pengawas melakukan pemantauan atau supervisi pembelajaran serta kehadirannya mengamati langsung aktivitas guru waktu pelaksanaan proses pembelajaran, melihat kesesuaian antara rencana pelaksanaan pembelajaran yang disiapkan guru dengan tindakan guru di kelas dan seluruh guru harus teramati. Penilaian pengawas terhadap guru di lapangan bukan sekedar formalitas, akan tetapi penilaian ini hendaknya menjadian acuan dalam memperbaiki pelaksanaan proses pembelajaran di sekolah.

Dari hasil analisis pelaksanaan supervisi akademik pengawas sekolah untuk pembimbingan/pelatihan tergolong cukup baik dengan skor 48 atau 60,00. Artinya bahwa pelaksanaan pembimbingan dan pelatihan sudah terlaksana, akan tetapi pengawas masih perlu meningkatkan kegiatan pembimbingan dan pelatihan dengan baik, pengawas sekolah harus proaktif melihat dan membantu guru-guru di sekolah tanpa harus menunggu guru-guru memintanya untuk dibimbing, masih banyak hal-hal yang belum dipahami sepenuhnya oleh guru terkait dengan pembelajaran, sehingga pengawas harus membantunya dan pengawas juga perlu meningkatkan kompetensinya terutama kompetensi supervisi akademik. 


\section{Simpulan}

Berdasarkan temuan dan analisis hasil, maka dapat disimpulkan sebagai berikut.

1. Pelaksanaan supervisi akademik pengawas SMK Negeri di Kabupaten Takalar untuk aspek pemantauan berdasarkan penilaian guru berada pada kategori cukup baik.

2. Pelaksanaan supervisi akademik pengawas SMK Negeri di Kabupaten Takalar untuk aspek penilaian berdasarkan penilaian guru berada pada kategori kurang baik.

3. Pelaksanaan supervisi akademik pengawas SMK Negeri di Kabupaten Takalar untuk aspek pembimbingan/pelatihan berdasarkan penilaian guru berada pada kategori cukup baik.

\section{Rekomendasi}

Berdasarkan hasil penilaian guru terhadap pelaksanaan supervisi akademik di SMK Negeri di Kabupaten Takalar, maka peneliti merekomendasikan beberapa hal sebagai berikut.

1. Kepada pengawas sekolah SMK dalam melakukan penilaian guru di sekolah agar lebih teliti dalam melaksanakan penilaian dengan melakukan pengamatan langsung di kelas kepada semua guru.

2. Kepada kepala Dinas Pendidikan, Kebudayaan, Pemuda Dan Olahraga, sebaiknya memberikan pelatihan secara kontinu dan perhatian pengawas sekolah agar dalam melaksanakan tugas melaksanakan supervisi akademik dalam aspek penilaian hendaknya dilakukan dengan teliti dengan melihat kondisi guru di kelas dalam proses pembelajaran kepada semua guru. 


\section{Ucapan Terimakasih}

Terimah kasih yang setulus-tulusnya kepada Prof. Dr. Andi Ihsan, M.Kes dan Prof. Dr. H. M. Sidin Ali, M.Pd, selaku pembimbing I dan II, yang telah banyak meluangkan waktunya untuk membimbing dan mengarahkan penulis. Ucapan terima kasih juga kepada tim penguji, yaitu Prof. Dr. Patta Bundu, M. Ed dan Prof. Dr. Ruslan, M.Pd yang banyak memberikan masukan yang sangat berarti dalam penyusunan laporan penelitian ini.

Selanjutnya Ucapan terima kasih pula kepada Direktur Program Pascasarjana Universitas Makassar, Asisten I, Asisten II, dan Ketua Program Studi Prof. Dr. Ruslan, M.Pd yang telah memberikan kemudahan kepada penulis, baik pada saat mengikuti perkuliahan, maupun pada saat pelaksanaan penelitian dan penyusunan laporan, semoga bantuan dan bimbingan yang diberikan mendapat pahala dari Allah SWT.

Terimah kasih pula penulis sampaikan kepada Dit. P2TK Dikmen. Direktorat Jenderal Pendidikan Menengah, Kementerian Pendidikan dan Kebudayaan Republik Indonesia atas bantuan beasiswa secara penuh kepada penulis selama dua tahun. Ucapan terimah kasih kepada Pemda Kab. Takalar dan Dikpora yang telah memberi tugas belajar untuk mengikuti pendidikan S2 pada Program Pascasarjana Universitas Negeri Makassar. Terimahkasih Kepada Kepala SMKN 1 Takalar, Kepala SMKN 2 Takalar, Kepala SMKN 3 Takalar, Kepala SMKN 4 Takalar, Kepala SMKN 5 Takalar, Kepala SMKN 6 Takalar dan Kepala SMKN 7 Takalar, yang telah memberi izin serta turut membantu dalam penelitian ini. 


\section{Daftar Pustaka}

Asmani, J.M. 2012. Tips Efektif Supervisi Pendidikan Sekolah. Yogyakarta: Dipa Press.

Direktorat Jenderal Manajemen Pendidikan Dasar dan Menegah 2010. Instrumen Standar Proses: Supervisi, Monitoring, \& Evaluasi : Jakarta Kementerian Pendidikan Nasional.

Herris. 2011, Pengertian Bimbingan Menurut Ahli. (Online). http://herrystw.wordpress.com/2011/05/23/pengertian-bimbingan-menurut-ahli/ Diakses Tgl 2 Pebruari 2014.

Iskandar, Akbar. 2013. "PENGEMBANGAN PERANGKAT PENILAIAN PSIKOMOTOR DI SEKOLAH MENENGAH KEJURUAN.” Jurnal Inspiration 3(1):37-46.

Masaong, A.K. 2012. Supervisi Pembelajaran Dan Pengembangan Kapsitas Guru. Gorontalo: Alfabeta.

Riduwan. 2009. Metode \& Teknik Menyusun Proposal Penelitian. Bandung: Alfabeta.

Sudjana, N. 2011b. Supervisi Pendidikan Konsep Dan Aplikasinya Bagi Pengawas Sekolah. Bekasi: Binamitra Publising.

Wastandar, \& Dharma, 2012a. Pemantauan Pelaksanaan Standar Nasional Pendidikan (Panduan Bagi Pengawas sekolah). Bekasi: Binamitra Publising. 2012b. Pengawas Dan Kepengawasan. Bekasi: Binamitra Publising.

\& Dharma. 2013. Menyusun Program Pengawas (Panduan Bagi Pengawas sekolah). Bekasi: Binamitra Publising.

Suhardan, D. 2009. Manajemen Pendidikan. Bandung: Alfabeta.

Sukmadinata, N.S. 2004. Landasan Psikologi Proses Pendidikan. Bandung : PT. Remaja Rosda Karya.

Peraturan Menteri Penberdayaan Aparatur Negara Dan Reformasi Birokrasi No.21 Tahun 2010 tentang Jabatan Fungsional Sekolah dan Angka Kreditnya. 
ARTIKEL PENELITIAN

PENILAIAN PELAKSANAAN SUPERVISI AKADEMIK PENGAWAS SMK NEGERI DI KABUPATEN TAKALAR

Assement of the Implementation of Academic Supervision of Supervisors at SMKN in Takalar District

ABDUL AZIS

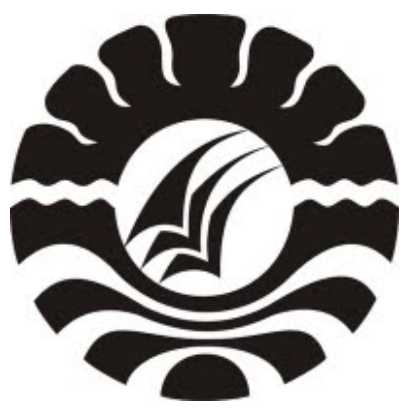

PROGRAM PASCASARJANA

UNIVERSITAS NEGERI MAKASSAR

2014 